\title{
The impact of the climate change on discharge of Suir River Catchment (Ireland) under different climate scenarios*
}

\author{
S. Wang, R. McGrath, T. Semmler, C. Sweeney, and P. Nolan \\ Met Eireann, Glasnevin Hill, Dublin 9, Ireland \\ *This paper was presented during the 1st General Assembly of EGU 2005 at the session NH1.05 titled "Diagnosis, modelling \\ and forecasting of meteorological and hydrological hazards produced by extreme weather and climate change".
}

Received: 21 July 2005 - Revised: 15 March 2006 - Accepted: 15 March 2006 - Published: 22 May 2006

\begin{abstract}
The impact of climate change on local discharge variability is investigated in the Suir River Catchment which is located in the south-east of Ireland. In this paper, the Rossby Centre Regional Atmospheric Model (RCA) is driven by different global climate data sets. For the past climate (1961-2000), the model is driven by ECMWF reanalysis (ERA-40) data as well as by the output of the general circulation models (GCM's) ECHAM4 and ECHAM5. For the future simulation (2021-2060), the model is driven by two GCM scenarios: ECHAM4_B2 and ECHAM5_A2. To investigate the influence of changed future climate on local discharge, the precipitation of the model output is used as input for the HBV hydrological model. The calibration and validation results of our ERA-40 driven present day simulation shows that the HBV model can reproduce the discharge fairly well, except the extreme discharge is systematically underestimated by about $15-20 \%$. Altogether the application of a high resolution regional climate model in connection with a conceptual hydrological model is capable of capturing the local variability of river discharge for present-day climate using boundary values assimilated with observations such as ERA-40 data. However, using GCM data to drive RCA and HBV suggests, that there is still large uncertainty connected with the GCM formulation: For present day climate the validation of the ECHAM4 and ECHAM5 driven simulations indicates stronger discharge compared to the observations due to overprediction of precipitation, especially for the ECHAM5 driven simulation in the summer season. Whereas according to the ECHAM4_B2 scenario the discharge generally increases - most pronounced in the wet winter time, there are only slight increases in winter and considerable decreases in summer according to the ECHAM5_A2 scenario. This also leads to a different behaviour in the evolution of return levels of extreme discharge events: Strong increases
\end{abstract}

Correspondence to: S. Wang

(shiyu.wang@met.ie) according to the ECHAM4_B2 scenario and slight decreases according to the ECHAM5_A2 scenario.

\section{Introduction}

The IPCC has stated that mean surface temperatures may rise $0.3-0.6^{\circ}$ Celsius per decade in the 21 st century (IPCC, 2001) as a result of anthropogenic influences. As increased temperatures will lead to greater amounts of water vapour in the atmosphere and an accelerated global water cycle, it can be expected that river catchment areas will be exposed to a greater risk of flooding.

To investigate the possible future development of the frequency and intensity of flooding events a hydrological model can be forced with the output from a climate model. However, because of the relatively coarse resolution of general circulation models (GCM), it is difficult to capture the relatively inhomogeneous spatial distribution of precipitation due to an inadequate description of orography and land use. The high horizontal resolution of a regional climate model $(\mathrm{RCM})$ is more appropriate for resolving the small scale features of orography and land use, that have a major influence on hydrological variables such as precipitation and runoff. Furthermore, significant efforts have been made to improve the representation of the land surface-atmosphere interaction, particularly for the hydrological component. The land surface parameterization scheme is an important component for the water cycle representation in a regional climate model. Because hydrological models need detailed precipitation information as an input, the high resolution of the RCM is ideal to capture the variability of precipitation (Gutowski et al., 2003). If the horizontal resolution of the RCM is not fine enough, for example, the bias of the modelled precipitation will lead to an unrealistic hydrological control run if the unmodified output is used to drive a hydrological model (Graham, 2000). The most important source of uncertainty in

Published by Copernicus GmbH on behalf of the European Geosciences Union. 


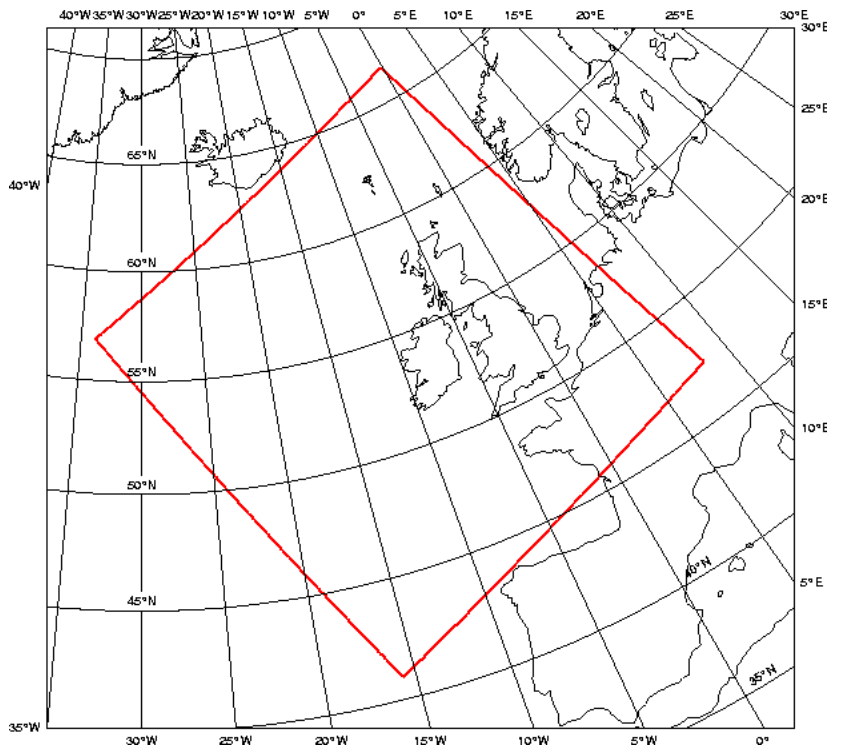

Fig. 1. Model domain.

estimating the hydrological response comes from the GCM with additional uncertainties linked to the local scale patterns in downscaling of temperature, precipitation and evapotranspiration in a specific drainage basin (Bergström et al., 2001; Gao et al., 2002).

Some impact studies of the climate change on flooding have been carried out in different countries and regions (Bergström et al., 2001; Pilling and Jones, 2002; Gao et al., 2002; Arnell, 2003). Depending on the spatial and temporal scales, and the aim of the study, different global and regional climate models have been used to translate the assumed climate change into a hydrological response. However, in all of these studies the horizontal resolution of the climate models was relatively coarse (50 km or more). None of the studies looked at extreme events on the base of daily precipitation and river discharge, both of which are crucial in terms of estimating possible impacts on society; the focus was on mean climate values.

Over Ireland, impact of climate change on the hydrological cycle has been assessed by a conceptual hydrological model (Charlton and Moore, 2003). The aim of our study is to examine the changes in extreme discharge events for Ireland due to climate change, using the output of a high resolution RCM simulation applied to the Suir river catchment area as a test case. For this purpose, two scenarios are investigated. One is the IPCC A2 scenario with comparably strong greenhouse gas (GHG) emissions due to regionally orientated economic growth. It projects higher GHG emissions than the IS92a scenario (which GHG concentrations increase by $1 \%$ per year after 1990); the other scenario is the IPCC B2 scenario assuming more emphasis on regionally orientated environmental protection. Therefore it produces lower GHG emissions than the IS92a scenario.
For the hydrological model, next to the catchment characteristics including topography and maximum soil moisture storage, the most important processes in the context of climate change and river discharge are known to be precipitation and evapotranspiration. In this study, the precipitation values from a high resolution regional climate model simulations are used to drive the hydrological model in the catchment area.

\section{Methodology}

\subsection{Regional climate model}

The RCM used in this study is the Rossby Centre Regional Atmospheric Model (RCA) developed from the High Resolution Limited Area Model (HIRLAM). Most HIRLAM parameterisations have been retained in RCA, but RCA hosts a new land surface scheme and some hydrological processes are included (Rummukainen et al., 2001; Jones, 2001), i.e. soil moisture transfer includes Darcian flow and runoff is routed down the soil column as in the hydrological HBV model. For this study, the RCA model domain has been set up with a $0.12^{\circ}(13 \mathrm{~km})$ spherical, rotated latitude/longitude grid (Fig. 1). For considering the effect of the North Atlantic ocean, the model domain includes good parts of this ocean north, west and south of Ireland. There is a large scale jump between the GCM and RCM spatial resolution. However, this model setup has been validated extensively. The results suggest, that the model configuration is well able to capture the characteristics of present day climate (Wang et al., 2006; McGrath et al., 2005).

In this study, several global datasets are used to drive the RCA model. For the validation, atmospheric data from the ECMWF 40-year reanalysis project (ERA-40) (Uppala et al., 2005) (1961-2000) are used. This will help us to understand the performance of the model without any adverse effects coming from biases in the global climate model simulation. For the investigation of the influence of the future climate under different climate scenarios, the datasets from the global climate model ECHAM4 (Roeckner et al., 1996) and ECHAM5 (Roeckner et al., 2003) are used. One of the simulations is driven by ECHAM4 data consistent with the SRES-B2 scenario, the other one is driven by ECHAM5 data consistent with the SRES-A2 scenario. Both of the simulations are run for the time period 2021-2060. The control period for both the ECHAM4 and ECHAM5 driven RCA simulations is $1961-2000$.

\subsection{HBV hydrological model and description of the catch-} ments

For the river discharge simulation, the hydrological model HBV of the Swedish Meteorological and Hydrological Institute (SMHI) is used (Bergström, 1995; Lindström et al., 
1997). This model is a semi-distributed, conceptual hydrological model using sub-basins as the primary hydrological units; it takes into account area-elevation distribution and basic land-use categories (forest, open areas and lakes). Subbasins are considered in geographically or climatologically heterogeneous basins or catchment areas of large lakes. The model consists of a precipitation routine representing rainfall, a soil moisture routine determining actual evapotranspiration and controlling runoff formation, a runoff routine is the response function which transforms excess water from the soil moisture zone to runoff. This model has been evaluated as one of the most appropriate models for the assessment of climate change impacts on peak discharge and flood frequency analysis (Passchier, 1996); it has been widely used in Europe and other parts of the world in climate change studies (Liden and Harlin, 2000; Bergström et al., 2001; Menzel and Burge, 2002).

For the analysis of the performance of the HBV model driven by dynamically downscaled rainfall from the RCA model, the Suir river catchment located in the south-east of Ireland is studied (Fig. 2). This catchment covers $2173 \mathrm{~km}^{2}$. Inside the catchment there is a hydrological observation station in Clonmel, which produces good quality discharge data. This enables us to do a careful calibration and validation of the hydrological model. Booij (2005) studied the impact of spatial model resolution on river discharge using the HBV model. They chose different numbers of sub-basins: 1,15 and 118. The observed hydrograph is simulated realistically by all of the three models. Therefore due to the lack of sufficient observed precipitation data, only one sub-basin is used in this study and five rain gauge stations data are used for the calibration. The potential evapotranspiration PE is calculated according to the method developed by Priestly and Taylor (1972), which takes into account temperature and radiation values. Due to the fairly good simulation of temperature and radiation (McGrath et al., 2005), the difference between the 40 years averaged monthly PE as calculated using observed and simulated temperature and radiation is less than 5\% in all seasons (only the annual cycle of PE is used in $\mathrm{HBV}$ ). In any case the monthly mean PE as calculated using observed temperature and radiation is used for the ERA-40 driven simulation, which helps us to judge the pure effect of the precipitation bias in the climate model simulation on the discharge simulation. For the ECHAM driven simulations, $\mathrm{PE}$ as calculated from RCA temperature and radiation values has been used. The PE values are larger by about $5 \%$ in both ECHAM driven future simulations compared to the control simulations, which is due to changed temperature and radiation values.

\subsection{Calibration}

In the HBV model, there are a number of parameters, which need to be calibrated with observed discharge values. There are two sets of parameters. The main parameters of the soil

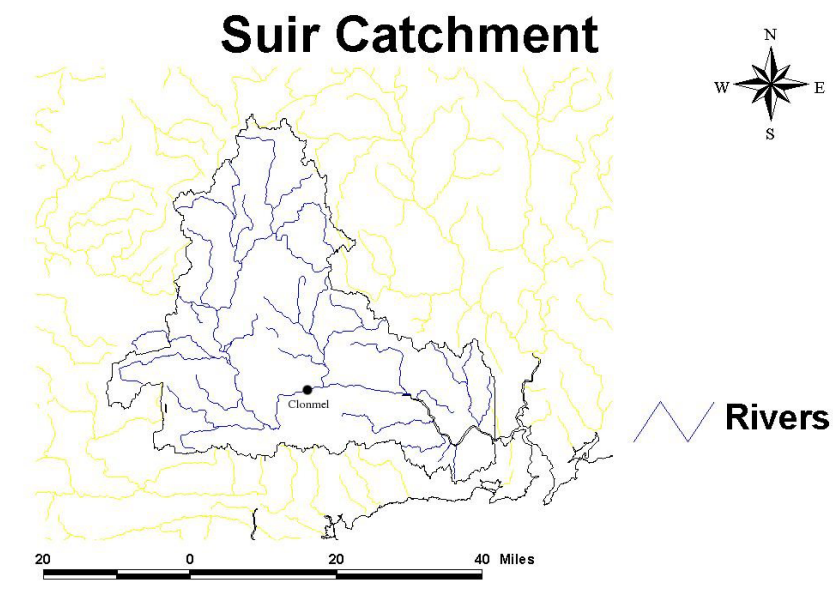

Fig. 2. Suir catchment area and river network.

moisture parameter set are FC (maximum soil moisture storage in millimeter), LP (fraction of FC above which potential evapotranspiration occurs and below which evapotranspiration will be reduced) and the coefficient BETA (determining the relative contribution to runoff from a millimeter of precipitation at a given soil moisture deficit). These parameters are dependent on the properties of the catchment, such as the land use type, the wilting point and soil porosity. They will affect the simulated discharge volume. The other parameter set includes runoff parameters such as ALFA (measure of the non-linearity for runoff), HQ (the higher flow level at which the recession rate KHQ is assumed) and KHQ (recession coefficient at HQ). These parameters influences the shape of the hydrograph (SMHI, 2004). Because of the uncertainty of the parameters, the Monte Carlo Random Sampling (MCRS) method is popularly used for parameter estimation (Lamb, 1999; Liden and Harlin, 2000) in the calibration of the model. However, because the program source code is not available, the above method is difficult to apply in our case. Therefore, quasi-stratified sampling in the form of Latin Hypercube Sampling (McKay et al., 1979) is used. The limited sampling numbers of this method can produce similar results to the Monte Carlo approach (Yu et al., 2001; Murphy et al., 2004). In the previous HBV studies, much experience has been gained in the parameter estimation, which is used to acquire the reasonable ranges of the main parameters in our study (Uhlenbrook et al.,1999; Seibert, 1999; Krysanova et al., 1999; Diermanse, 2001; SMHI, 2004; Booij, 2005). FC ranges from 200 to 500, LP from 0.6 to 1.0, BETA from 1.0 to 5.0, ALFA from 0.8 to 1.1 , KHQ from 0.08 to 0.14 and HQ is fixed to 3.0. According to Murphy et al. (2004) and the range of the different parameters, 50-100 sampling numbers are used in the calibration.

For the calibration of the Suir catchment, observed precipitation data for the period January 1960 to December 1964, which includes relatively dry and wet years, and monthly mean climate potential evapotransipiration values are used to 


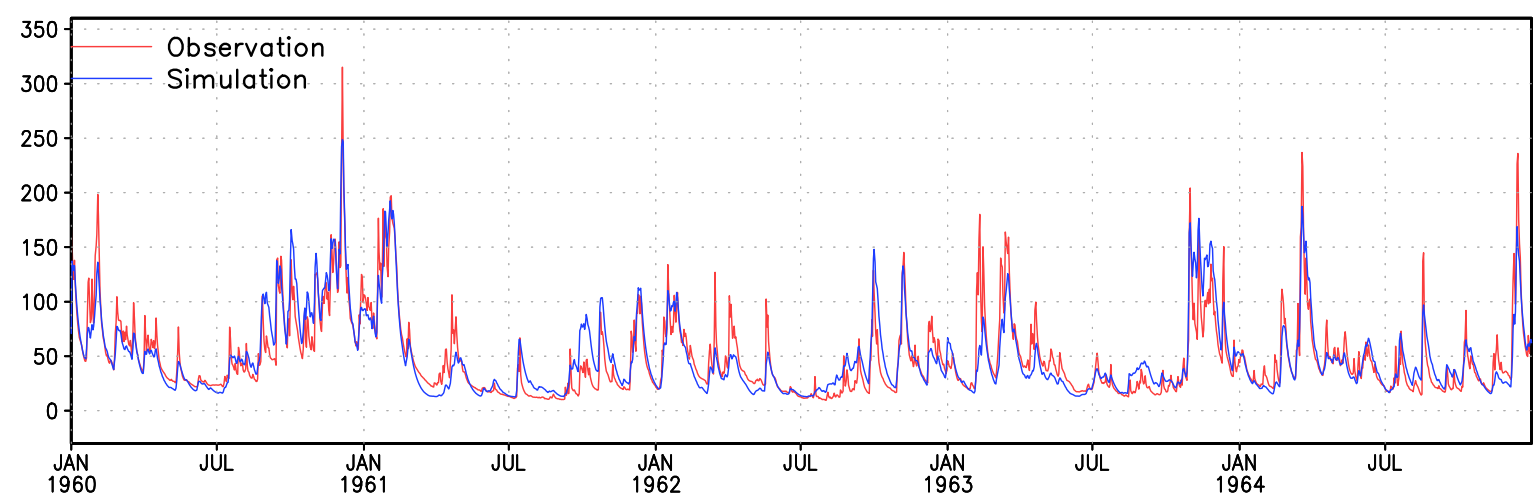

Fig. 3. Observed and simulated (using observed precipitation as the input) discharge $\left[\mathrm{m}^{3} / \mathrm{s}\right]$.

Table 1. Daily precipitation statistics in Suir river catchment for the observation and simulation.

\begin{tabular}{lccccccc}
\hline & OBS & ERA40 & ERA40 & ECHAM4 & ECHAM4 & ECHAM5 & ECHAM5 \\
& $(1960-1964)$ & $(1961-1964)$ & $(1961-2000)$ & $(1961-2000)$ & $(2021-2060)$ & $(1961-2000)$ & $(2021-2060)$ \\
\hline Average (mm) & 2.78 & 3.33 & 3.86 & 4.31 & 4.59 & 4.63 & 4.6 \\
Standard deviation $(\mathrm{mm})$ & 4.83 & 4.36 & 5.02 & 5.98 & 6.51 & 5.97 & 6.11 \\
99\% percentile $(\mathrm{mm})$ & 22.6 & 19.56 & 23.63 & 27.44 & 29.69 & 26.83 & 28.12 \\
95\% percentile $(\mathrm{mm})$ & 12.3 & 11.8 & 13.89 & 16.09 & 17.32 & 16.39 & 16.87 \\
25\% percentile $(\mathrm{mm})$ & 0.05 & 0.48 & 0.57 & 0.36 & 0.38 & 0.5 & 0.45 \\
\hline
\end{tabular}

drive the HBV model. The actual catchment area is shown in Fig. 2. Although insufficient observation data coverage limited the duration of the calibration to 5 years, the minimum requirement according to the model documentation of SMHI (SMHI, 2004), which recommends the use of 5-10 years of calibration data, is still met. In order to assess the performance of the model, the Nash-Sutcliffe efficiency coefficient $R^{2}$ (Nash and Sutcliffe, 1970) and the relative error $R E$ are calculated.

$R^{2}=1-\frac{\sum_{i=1}^{i=N}\left[Q_{s}(i)-Q_{o}(i)\right]^{2}}{\sum_{i=1}^{i=N}\left[Q_{o}(i)-\bar{Q}_{o}\right]^{2}}$

$\mathrm{RE}=\frac{\sum_{i=1}^{i=N}\left|\left[Q_{s}(i)-Q_{o}(i)\right]\right|}{\sum_{i=1}^{i=N} Q_{o}(i)}$

where $Q_{s}$ represents computed discharge, $Q_{o}$ is observed discharge and $\bar{Q}_{o}$ is the mean of $Q_{o}$ over the calibration period.

For the calibration of the Suir catchment, $\mathrm{R}^{2}$ reached 0.787, which implies that the model has a good performance in this area (Fig. 3). Except for the peak values, which are slightly underestimated, the variation of the simulated discharge coincides with the observed discharge fairly well from visual inspection. This is also confirmed by the smaller RE value, which is only 0.24 .

\section{Results}

\subsection{Validation}

After the successful calibration of the HBV model using the observed climate variables, the dynamically downscaled precipitation is used to drive the HBV model. The performance of the RCA model is firstly investigated. Compared with the observed precipitation, the RCA model has simulated the basic precipitation pattern over Ireland fairly well, even though it is slightly overestimated in the midland areas. This is possibly due to too many light precipitation events in the model (Table 1). In mountainous areas the precipitation is slightly underestimated which could be partly due to the representation of the orography in the model, which is still smoother than in reality even at the high resolution of $13 \mathrm{~km}$. A spatial pattern analysis has shown that the seasonal and interannual variability is reproduced reasonably well (Wang et al., 2006; McGrath et al., 2005).

As an example Fig. 4 shows 10 years of the ERA- 40 driven RCA simulation time series of discharge in the Suir catchment between 1981 and 1990 compared to the observations. Generally, the evolution of the simulated discharge shows good agreement with the observed discharge. This is also 


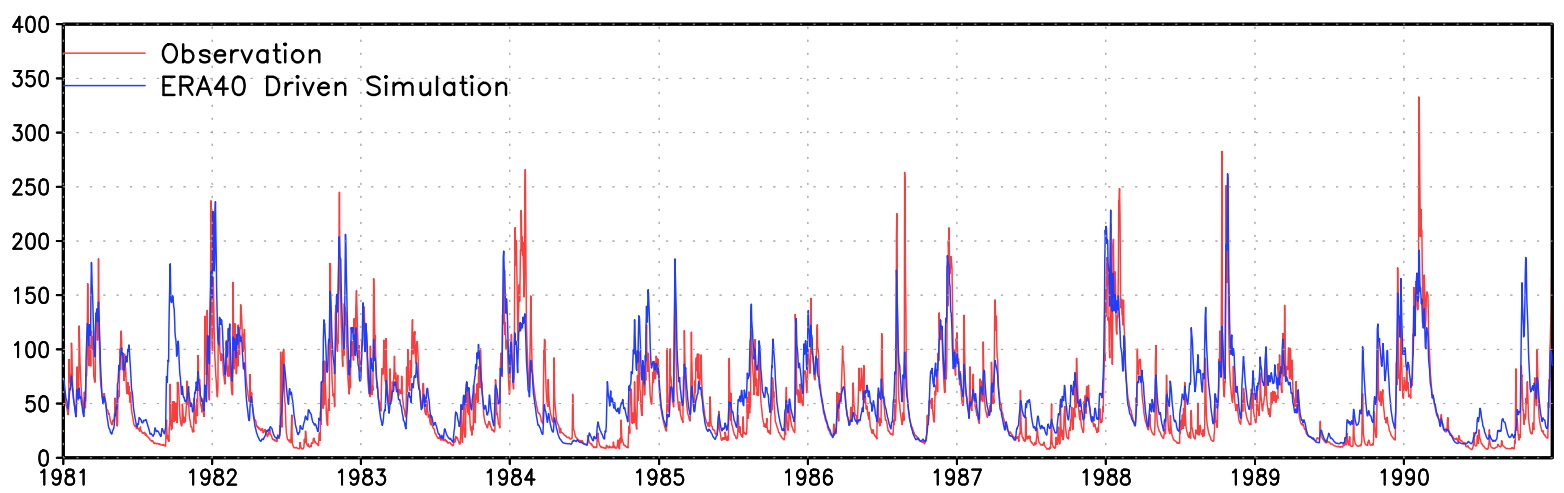

Fig. 4. Observed and simulated (ERA-40 driven simulation) discharge $\left[\mathrm{m}^{3} / \mathrm{s}\right]$.

Table 2. Daily discharge statistics in Suir river catchment for the observation and simulation.

\begin{tabular}{lccccccc}
\hline & OBS & ERA40 & ERA40 & ECHAM4 & ECHAM4 & ECHAM5 & ECHAM5 \\
& $(1960-1964)$ & $(1961-1964)$ & $(1961-2000)$ & $(1961-2000)$ & $(2021-2060)$ & $(1961-2000)$ & $(2021-2060)$ \\
\hline Average $\left(\mathrm{m}^{3} / \mathrm{s}\right)$ & 48.89 & 42.78 & 58.12 & 67.2 & 74.72 & 79.73 \\
Standard deviation $\left(\mathrm{m}^{3} / \mathrm{s}\right)$ & 36.99 & 25.2 & 37.48 & 45.06 & 55.55 & 46.63 & 47.25 \\
$99 \%$ percentile $\left(\mathrm{m}^{3} / \mathrm{s}\right)$ & 171.96 & 135.47 & 185.35 & 213.64 & 253.53 & 241.75 \\
$95 \%$ percentile $\left(\mathrm{m}^{3} / \mathrm{s}\right)$ & 126.79 & 96.93 & 132.13 & 158.28 & 173.65 & 162.14 & 169.83 \\
$25 \%$ percentile $\left(\mathrm{m}^{3} / \mathrm{s}\right)$ & 23.17 & 25.78 & 31.09 & 33.6 & 37.31 & 50.05 & 44.93 \\
\hline
\end{tabular}

true for the other three decades of the 40-year period. However, there are some discrepancies in the timing of the flood events, which lead to large differences between the observed and simulated discharge at specific times. Moreover, peak values are often underestimated, which caused a higher relative error, it reaches 0.4 . Because the agreement of observed and simulated precipitation is as good as the agreement of the discharge rates (see Tables 1 and 2), the underestimation of the heavy precipitation intensities caused the underestimation of the discharge peaks. Especially the higher percentile precipitation is underestimated. On the whole, the simulation is a little worse compared to the calibration; $\mathrm{R}^{2}$ only reaches 0.545 , while the correlation coefficient reaches 0.79 . This confirms that the model simulates the evolution of the discharge reasonably well, whereas the underestimated peak values caused the $\mathrm{R}^{2}$ value to be relatively low. Figure 5 gives return values of the maximum daily discharge of the observation and ERA-40 driven simulation calculated by generalized extreme value (GEV) method. The distribution of return values for the different return periods show a fair agreement, although they are systematically underestimated by about $15-20 \%$ in the simulation.

\subsection{Future climate change projection}

To investigate the effect of the climate change under different climate scenarios, the control climate is firstly evaluated.

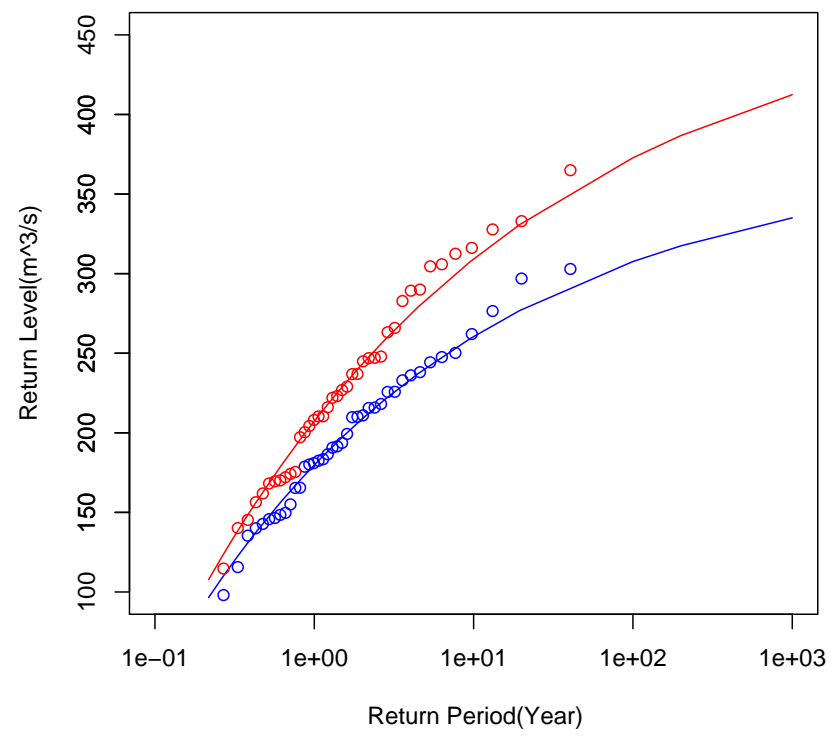

Fig. 5. Return values of observed (red) and simulated (ERA-40 driven simulation) (blue) maximum annual discharge (Circles: Values of maximum daily discharge per year, lines: Fit using generalized extreme value distribution).

Figure 6 shows the simulated discharge using ECHAM4 and ECHAM5 driven RCA simulation data to drive the HBV model. As for the ERA-40 driven simulation, the results for 


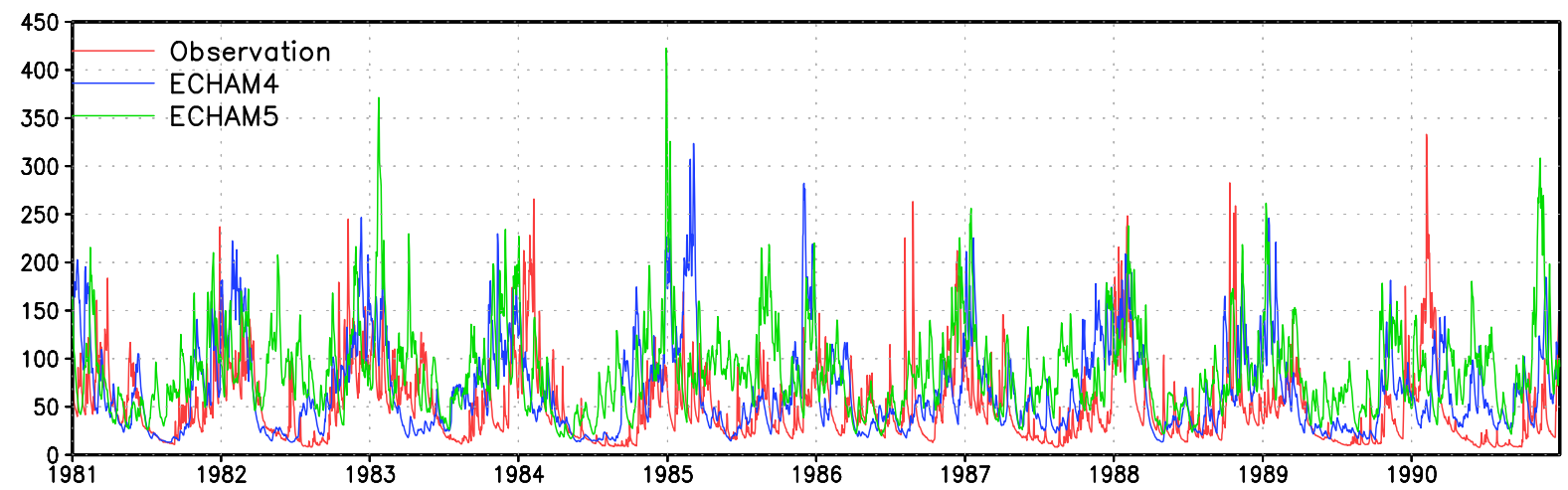

Fig. 6. Simulated discharge using the ECHAM4 and ECHAM5 driven RCA simulation and observed discharge $\left[\mathrm{m}^{3} / \mathrm{s}\right]$.

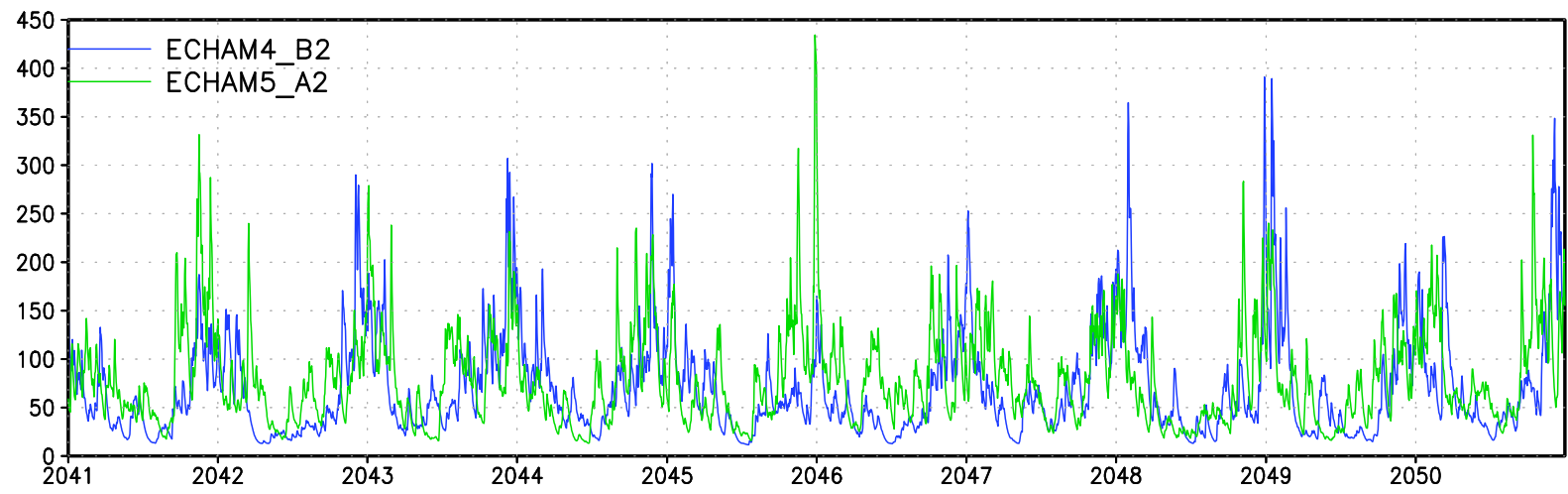

Fig. 7. Simulated discharge using the ECHAM4 and ECHAM5 driven RCA simulation for future $\left[\mathrm{m}^{3} / \mathrm{s}\right]$.

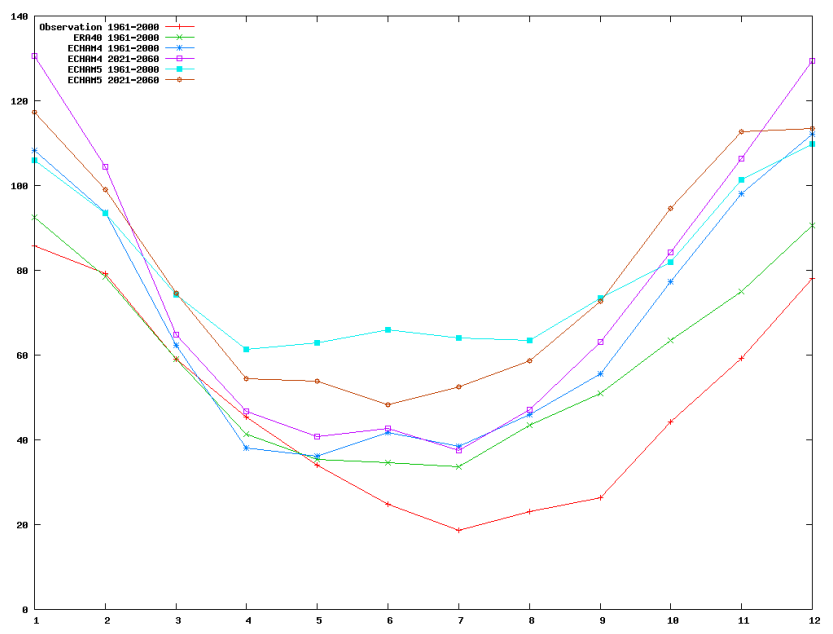

Fig. 8. Annual cycle of observed and simulated (driven by ERA40, ECHAM4 and ECHAM5 data) discharge, 1961-2000, compared with the simulated discharge for 2021-2060 driven by ECHAM4 and ECHAM5 data $\left[\mathrm{m}^{3} / \mathrm{s}\right]$.

the time period 1981-1990 are shown. In addition Fig. 8 shows the 40 year monthly mean discharge from all simula- tions compared to observations. The ECHAM4 driven simulation indicates slightly overpredicted discharge. The biggest difference between the ERA-40 and ECHAM4 driven simulation is in the winter season; there are only minor differences in the summer season. The ECHAM5 driven simulation shows an even stronger discharge overprediction than the ECHAM4 driven simulation. Whereas there are not much differences between ECHAM4 and ECHAM5 in winter, the overprediction gets particularly strong in the summer season in ECHAM5. This is also reflected by the mean precipitation; the ECHAM5 driven simulation tends to have higher mean precipitation (Table 1).

One reason for the even stronger overestimation of mean precipitation in the ECHAM5 driven simulation compared to the ECHAM4 driven simulation might be, from our analysis of the boundary data, that ECHAM5 overestimates the atmospheric humidity stronger than ECHAM4 if compared to ERA-40. Both ECHAM4 and ECHAM5 data show a too unstable stratification of the atmosphere compared to ERA-40 data.

A reason for the more severely underpredicted precipitation and discharge differences between the winter and the summer season in the ECHAM5 driven simulation compared to the ECHAM4 driven simulation might be a decreased 
pressure gradient in ECHAM5 compared to ECHAM4 in winter and an increased pressure gradient in summer. Thus the westerly flow is weaker in winter and stronger in summer.

Even if driven by ERA-40, the RCA model underestimates the amplitude of the seasonal cycle of precipitation leading to too high values in the summer season; at the same time, the simulated transition between the dry and the wet season is slower than observed (Wang et al., 2006). This feature of RCA even enhances the problem in the ECHAM5 driven RCA simulation.

To analyse the discharge variation in the future projection, 10 years of results between 2041 and 2050 are presented in Fig. 7. In addition Fig. 8 shows the monthly discharge averaged over 40 years for all present day and future climate simulations. For the future projection, the biggest difference between ECHAM4-B2 scenario and its control run is in the winter season, where the discharge increases by up to $20 \%$ in December and January while the summer discharge remains nearly unchanged. The ECHAM5-A2 scenario also shows increased discharge in the winter season, but an obvious decrease in the summer season. This shows that there is still considerable uncertainty in the global climate projections.

For present day climate the intensity and frequency of peak discharge values are generally similar between the ECHAM4 driven, ECHAM5 driven simulations and the observation data (Fig. 6), although the ECHAM5 driven simulation shows a few much more intense discharge events than observation data and the ECHAM4 driven simulation. Since ECHAM4 and ECHAM5 data do not include observational information, the peak events occur at different times.

The return value analysis (Fig. 9) shows that the intensity and frequency of heavy discharge events clearly increases according to the ECHAM4-B2 scenario, whereas a weak decrease can be seen in the ECHAM5-A2 scenario.

\section{Conclusions}

In this paper, the HBV model was applied to study the effect of the climate change on river discharge under different climate scenarios. The input data are taken from a high resolution regional climate model driven by different data sets. Concerning the performance of the precipitation simulation, the RCA simulation is firstly investigated (Wang et al., 2006). The local precipitation distribution is captured fairly well. The calibration and validation results of our ERA-40 driven present day simulation show that the HBV model can reproduce the discharge reasonably well. There is, however, a small overestimation of the discharge in the summer season and an underestimation of the intensity of extreme discharge events in the winter season. Investigating the ECHAM4 and ECHAM5 driven present day simulation, considerable differences become apparent. Both simulations clearly overpredict the discharge because of too much atmospheric moisture and a too unstable atmospheric stratification leading to too
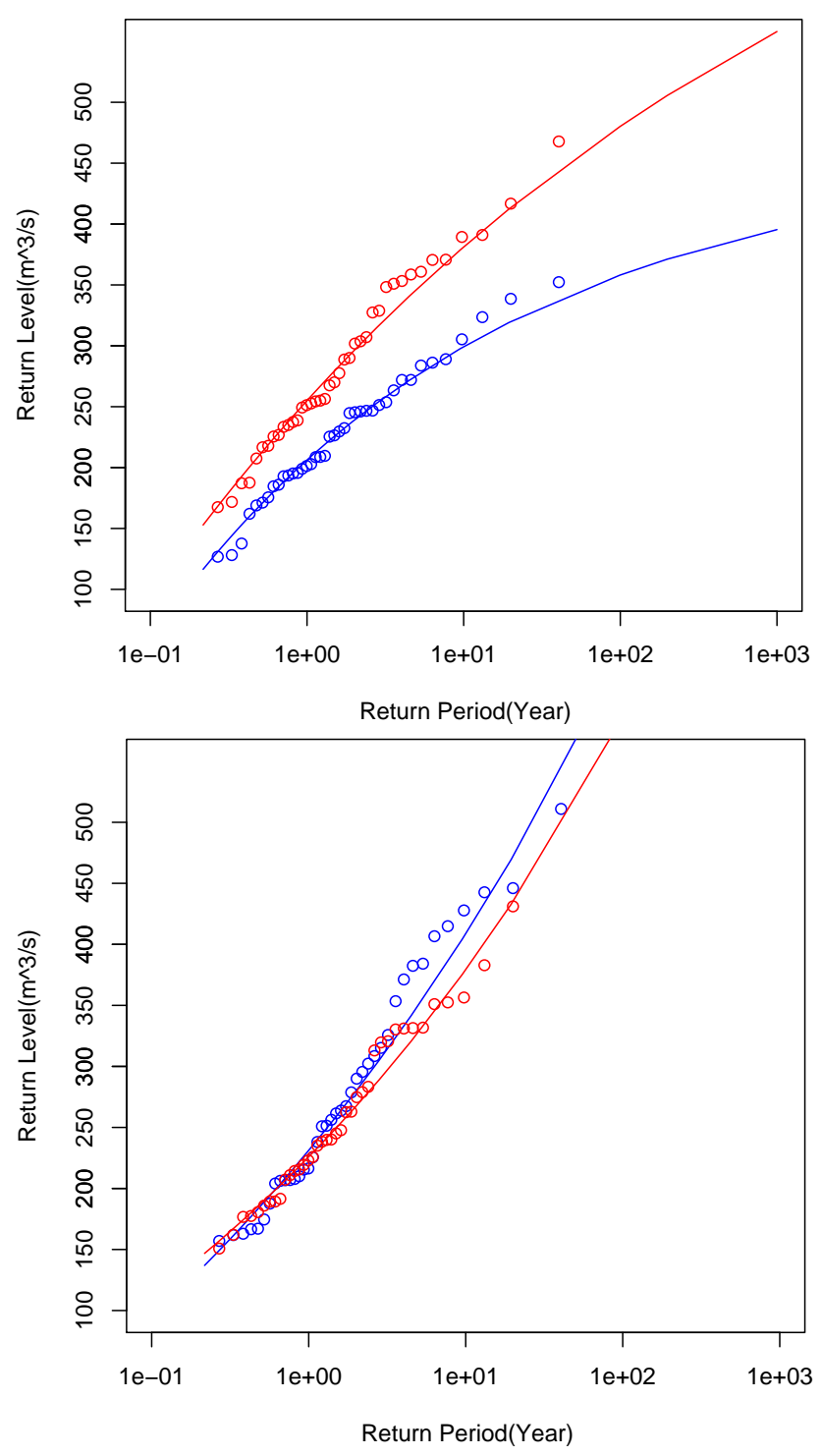

Fig. 9. Return values of the simulated maximum annual discharge using the ECHAM4 (a) and ECHAM5 (b) driven RCA simulation for the present-day (blue) and future climate (red).

much precipitation. The ECHAM5 driven simulation performs even worse especially in the summer season, where an intensified westerly flow leads to even more precipitation compared to the ECHAM4 driven simulation.

The results suggest that the application of a high resolution regional climate model in connection with a conceptual hydrological model is capable of capturing the local variability of river discharge, and the uncertainties are mainly due to the global datasets used in the study. This is also reflected in the future projection. The projection of the future climate shows a strong increase in the return levels of daily discharge values in the ECHAM4_B2 scenario but a 
slight decrease in the ECHAM5_A2 scenario. In the investigated Suir catchment, the 10-year return value of the maximum river discharge increases by more than $20 \%$ when using the moderate ECHAM4_B2 emission scenario for 20212060 compared to 1961-2000, whereas in the more aggressive ECHAM5_A2 scenario, the future extreme discharge even slightly decreases. These differences are connected to considerable differences in the mean annual cycle: The ECHAM5_A2 scenario shows a smaller discharge increase in the winter season than the ECHAM4_B2 scenario. In summer, the ECHAM5_A2 scenario shows a decrease in the discharge, whereas there is no change according to the ECHAM4_B2 scenario. This shows that there is still large uncertainty in the global climate projections, which are probably mainly connected with the GCM formulation and not so much with the chosen emission scenario.

Acknowledgements. The authors would like to thank the anonymous reviewers for their helpful comments. We also thank E. Nishimura for processing the observation and simulation precipitation data. This work was carried out under the Community Climate Change Consortium for Ireland (C4I) Project, funded by the following Irish agencies: Environmental Protection Agency (under the National Development Plan), Met Éireann, Sustainable Energy Ireland, and the Higher Education Authority. The work was also supported by the CosmoGrid project, funded under the Programme for Research in Third Level Institutions (PRTLI) administered by the Irish Higher Education Authority under the National Development Plan and with partial support from the European Regional Development Fund.

Edited by: M.-C. Llasat

Reviewed by: two referees

\section{References}

Arnell, N. W.: Relative effects of multi-decadal climatic variability and changes in the mean and variability of climate due to global warming: future streamflow in Britain, J. Hydrol., 270, 195-213, 2003.

Bergström, S.: The HBV model, Chapter 13 of Computer models of watershed hydrology, Water Resour. Publications, 443-476, 1995.

Bergström, S., Carlsson, B., Gardelin, M., Lindström, G., Pettersson, A., and Rummukainen, M.: Climate change impacts on the runoff in Sweden-assessments by global climate models, dynamical downscaling and hydrological modelling, Clim. Res., 16, 101-112, 2001

Booij, M. J.: Impact of climate change on river flooding assessed with different spatial model resolutions, J. Hydrol., 303, 176198, 2005.

Charlton, R. and Moore, S.: The Impact of Climate Change on Water Resources in Ireland, in: Climate Change: Scenarios and Impacts for Ireland, edited by: Sweeney, J., Brereton, T., Byrne, C., et al., Report to the Irish Environmental Protection Agency, ERTDI Report Series No. 15, 2003.

Diermanse, F. L. M.: Physically based modelling of rainfall-runoff processes, PhD thesis, Delft University Press, Delft, 2001.
Gao, S., Wang, J., Xiong, L., Yin, A., and Li, D.: A macro-scale and semi-distributed monthly water balance model to predict climate change impacts in China, J. Hydrol., 268, 1-15, 2002.

Graham, L. P.: Large-scale hydrological modelling in the Baltic basin, Division of Hydraulic Engineering, Dept of Civil and Environmental Engineering, Royal Institute of Technology, Report TRITA-AMI PHD 1033, Stockholm, 2000.

Gutowski, J. R., Decker, S. G., Donavon, R. A., Pan, Z. T., Arritt, R. W., and Takle, E. S.: Temporal-spatial scales of observed and simulated precipitation in central U.S. climate, J. Climate, 16, 3841-3847, 2003.

IPCC: Climate change 2001: The scientific basis, Houghton, J. T, Ding, Y., Griggs, G., Noguet, M., Van der Linden, P., Dai, X., Maskell, K., and Johnson, C. A., Cambridge: Cambridge University press, 2001.

Jones, C.: A brief description of RCA2, SWECLIM Newsletter, 11, 9-14, 2001.

Krysanova, V., Bronstert, A., and Muller-Wohlfeil, D. I.: Modelling river discharge for large drainage basins: from lumped to distributed approach, Hydrol. Sci. J., 44, 313-331, 1999.

Lamb, R.: Calibration of a conceptual rainfall-runoff model for flood frequency estimation by continuous simulation, Water Resour. Res., 35, 3103-3114, 1999.

Liden, R. and Harlin, J.: Analysis of conceptual rainfall-runoff modelling performance in different climates, J. Hydrol., 238, 231-247, 2000.

Lindström, G., Johansson, B., Persson, M., Gardelin, M., and Bergström, S.: Development and test of the distributed HBV-96 model, J. Hydrol., 201, 272-288, 1997.

McGrath, R., Nishimura, L., Nolan, P., Ratnam, J. V., Semmler, T. Sweeney, C., and Wang, S.: Community climate change consortium for Ireland (C4I) 2004 annual report, Met Eireann, Dublin, Ireland, 1-118, 2005.

McKay, M. D., Conover, W. J., and Beckman, R. J.: A comparison of three methods for selection values of input variables in the analysis of output from a computer code, Technometrics, 2, 239$245,1979$.

Menzel, L. and Burger, G.: Climate change scenarios and runoff response in the Mulde catchment (Southern Elbem Germany), J. Hydrol., 267, 53-64, 2002.

Murphy, C., Fealy, R., Charlton, R., and Sweeney, J.: Catering for uncertainty in a conceptual rainfall runoff model: model preparation for climate change impact assessment and the application of GLUE using Latin Hypercube Sampling, Proceedings of the National Hydrology Seminar, Tullamore, 64-74, 2004.

Nash, J. E. and Sutcliffe, J. V.: River flow forecasting through conceptual models 1: a discussion of principles, J. Hydrol., 10, 282 290, 1970.

Passchier, R. H.: Evaluation hydrological model packages, Technical Report Q2044, WL/Delft Hydraulics, Delft, 1996.

Pilling, C. G. and Jones, J. A. A.: The impact of future climate change on seasonal discharge, hydrological processes and extreme flows in the Upper Wye experimental catchment, midWales, Hydrol. Processes, 16, 1201-1213, 2002.

Priestley, C. H. B. and Taylor, R. J.: On the assessment of surface heat flux and evaporation using large-scale parameters, Mon. Wea. Rev., 100(2), 81-92, 1972.

Roeckner, E., Arpe, K., Bengsson, L., Christoph, M., Claussen, M., Duemenil, L., Esch, M., Giorgetta, M., Schlese, U., 
Schulzweida, U., Giorgetta, M., and Schlese, U.: The Atmospheric General Circulation Model ECHAM-4: Model Description and Simulation of Present-Day-Climate, Max-Planck Institute for Meteorology, Report No. 218, Hamburg, Germany, 1-90, 1996.

Roeckner, E., Bauml, G., Bonaventura, L., Brokopf, R., Esch, M., Giorgetta, M., Hagemannn, S., Kirchner, I., Kornblueh, L., Manzini, E., Rhodin, A., Schlese, U., Schulzweida, U., and Tompkins, A.: The Atmospheric General Circulation Model ECHAM5 Part I: Model Description, Max-Planck Institute for Meteorology, Report No. 349, Hamburg, Germany, 1-127, 2003.

Rummukainen, M., Räisänen, J., Bringfelt, B., Ullerstig, A., Omstedt, A., Willén, U., Hansson, U., and Jones, C.: A regional climate model for northern Europe: model description and results from the downscaling of two GCM control simulations, Climate Dynamics, 17, 339-359, 2001.

Uhlenbrook, S., Seibert, J., Leibundgut, C., and Rodhe, A.: Prediction uncertainty of conceptual rainfall-runoff models caused by problems in identifying model parameters and structure, Hydrol. Sci. J., 44, 779-797, 1999.
Uppala, S. M., Kållberg, P. W., Simmons, A. J., Andrae, U., da Costa Bechtold, V., Fiorino, M., Gibson, J. K., Haseler, J., Hernandez, A., Kelly, G. A., Li, X., Onogi, K., Saarinen, S., Sokka, N., Allan, R. P., Andersson, E., Arpe, K., Balmaseda, M. A., Beljaars, A. C. M., van de Berg, L., Bidlot, J., Bormann, N., Caires, S., Dethof, A., Dragosavac, M., Fisher, M., Fuentes, M., Hagemann, S., Hólm, E., Hoskins, B. J., Isaksen, L., Janssen, P. A. E. M., McNally, A. P., Mahfouf, J. F., Jenne, R., Morcrette, J. J., Rayner, N. A., Saunders, R. W., Simon, P., Sterl, A., Trenberth, K. E., Untch, A., Vasiljevic, D., Viterbo, P., and Woollen, J.: The ERA-40 reanalysis, Quart. J. Roy. Meteorol. Soc., 131, 2961-3012, 2005.

Seibert, J.: Regionalisation of parameters for a conceptual rainfallrunoff model, Agric. For. Meteorol., 89, 279-293, 1999.

SMHI: Integrated hydrological modelling system (IHMS), Manual version 4.5, SMHI, Norrköping, 2004.

Wang, S., McGrath, R., Semmler, T., and Sweeney, C.: Validation of simulated patterns over Ireland for the period 1961-2000, Int. J. Climatol., 26, 251-266, 2006.

Yu, P. S., Yang T. C., and Chen, S. J.: Comparison of uncertainty analysis methods for a distributed rainfall runoff model, J. Hydrol., 244, 43-59, 2001. 